University of Windsor

Scholarship at UWindsor

2008

\title{
Youth ice hockey coaches' perceptions of a team-building intervention program
}

Julie Newin

Gordon A. Bloom

Todd M. Loughead

University of Windsor

Follow this and additional works at: https://scholar.uwindsor.ca/humankineticspub

Part of the Kinesiology Commons, and the Sports Sciences Commons

\section{Recommended Citation}

Newin, Julie; Bloom, Gordon A.; and Loughead, Todd M.. (2008). Youth ice hockey coaches' perceptions of a team-building intervention program. Sport Psychologist, 22 (1), 54-72.

https://scholar.uwindsor.ca/humankineticspub/12

This Article is brought to you for free and open access by the Faculty of Human Kinetics at Scholarship at UWindsor. It has been accepted for inclusion in Human Kinetics Publications by an authorized administrator of Scholarship at UWindsor. For more information, please contact scholarship@uwindsor.ca. 


\title{
Youth Ice Hockey Coaches' Perceptions of a Team-Building Intervention Program
}

\author{
Julie Newin and Gordon A. Bloom \\ McGill University \\ Todd M. Loughead \\ University of Windsor
}

\begin{abstract}
The purpose of the current study was to explain youth ice hockey coaches' perceptions of the effectiveness of a team-building intervention program. Eight Peewee-level hockey coaches implemented the same team-building activities with their teams throughout the regular season. Data were gathered using 3 methods. Specifically, coaches answered questions on a pre- and postintervention form after each team-building activity, coaches' behaviors were observed by members of the research team, and each coach completed a semistructured exit interview after the completion of the regular season. Results highlighted the benefits of the team-building intervention program. Specifically, coaches felt athletes enjoyed this experience and improved or acquired a variety of important life skills and abilities. Coaches also felt that athletes bonded during activities and improved their abilities to work together as a group. Finally, coaches felt that their own personal communication skills improved.
\end{abstract}

Regular physical activity has numerous physiological (e.g., Haskell, 1994), cognitive (e.g., Etnier et al., 1997), and psychological (e.g., Landers \& Petruzzello, 1994) benefits for individuals of all ages (Carron, Hausenblas, \& Estabrooks, 2003). A major component of physical activity for youth is participation in team sports at both the recreational and competitive levels (cf. Wankel \& Mummery, 1996). Unfortunately, youth-sport participation begins declining after the age of 12; this finding is especially critical given that it is also a crucial time for the development of children's social skills and self-esteem (Hedstrom \& Gould, 2004; Lindner \& Johns, 1991). A number of reasons have been proposed to account for this dropout behavior. These include individual aspects such as lack of desire and environmental aspects including negative experiences with coaches (Wankel \& Mummery).

In Canada, attention to appropriate coaching behaviors is central to various coach-education programs including those conducted by the National Coach Certification Program (NCCP). One of the mandates of the NCCP is to establish

Newin and Bloom are with the Dept. of Kinesiology and Physical Education, McGill University, Montreal, Quebec H2W 1S4, Canada. Loughead is with the Dept. of Kinesiology, University of Windsor, Ontario, Canada. 
effective programs, usually in the form of workshops, that will enhance the sporting environment and improve coaching behaviors (Coaching Association of Canada, 2007). These workshops primarily focus on skill analysis, practice planning, injuries, nutrition, and tactical components of sport. Although the importance of these workshops cannot be undervalued, most of what coaches learn focuses on factors that influence individual outcomes in athletes. Very little information is presented, however, that explains how coaches can influence the team environment. This is alarming because a link has been established between the team environment and a variety of outcomes such as athlete satisfaction (e.g., Riemer \& Chelladurai, 1995; Riemer \& Toon, 2001), improved social support (e.g., Bloom \& Stevens, 2002), adherence (e.g., Spink \& Carron, 1993), future sport participation (e.g., Spink, 1995), and cohesion (e.g., Prapavessis \& Carron, 1997). Consequently, youth-sport participants might benefit from coaches who are trained to create a positive team environment.

With respect to improving the team environment, Smith and Smoll (1997) suggested that coaches could develop a more positive team atmosphere by implementing team-building techniques. Team building is viewed as a process to enhance the cohesiveness or unity of a team (Beer, 1980; Newman, 1984). To date, research on team building with youth has been used successfully in physical education classes (e.g., Ebbeck \& Gibbons, 1998; Gibbons \& Black, 1997; Glover \& Midura, 1992). One such program is Team Building Through Physical Challenges (TBPC; Glover \& Midura, 1992; Midura \& Glover, 2005), which involves intellectual, physical, and emotional problem-solving tasks and challenges along with emphasizing elements of fun and adventure. Gibbons and Black tested the effectiveness of a TBPC program on the self-concepts of seventh- and eighth-grade students. Activities focused on teamwork, organization, communication, and cooperation. Their results revealed that participants in the team-building intervention experienced increased self-perceptions of athletic competence, social acceptance, scholastic competence, and global self-worth compared with the control group. Similar results were found by Ebbeck and Gibbons in their investigation of the effect of a TBPC program on the self-conceptions of sixth- and seventh-grade students. Their postintervention results revealed that both male and female students in the team-building group were significantly higher on perceptions of global self-worth, athletic competence, physical appearance, and social acceptance than the control group.

Although the findings using team-building challenges with children in physical education classes are promising, the conceptual framework that guided the research has not been articulated. As Brawley and Paskevich (1997) noted, this has historically been one of the problems plaguing team-building research. One framework that might prove useful for team-building interventions with youth is Carron and Spink's (1993) conceptual model of team building. This model is linear in nature, consisting of inputs, throughputs, and outputs. Specifically, the inputs consist of the team environment and team structure. In regard to the team environment, one factor highlighted by Carron and Spink was distinctiveness. The authors noted that when the team's environment was unique, team members developed a stronger sense of being a part of a team. As for team structure, two factors were highlighted: individual positions and team norms. It was noted that having team members occupy a specific position in a team and developing collective expectations would contribute to a stronger sense of being a part of a team. 
In turn, the inputs influenced the throughput of team processes, which included communication and team sacrifices. For instance, Carron and Spink noted that team members who communicated effectively created a positive team atmosphere. In addition, the authors pointed out that when an individual made a sacrifice for the team, commitment to the team was enhanced. Finally, these throughputs influence the output of team cohesion.

Although no research to our knowledge has used the Carron and Spink (1993) conceptual model with youth, it has been shown to be useful in both the exercise and sport settings with adult participants. In regard to the exercise environment, Carron and colleagues (e.g., Carron \& Spink; Estabrooks \& Carron, 1999) found that exercisers exposed to a team-building intervention had higher perceptions of task cohesion than those in the control condition. Furthermore, the participants in the team-building intervention were less likely to withdraw from the program or arrive late for class than individuals in the control condition.

Besides the exercise setting, research using team-building interventions has been used in both adult recreational (Prapavessis, Carron, \& Spink, 1996) and elite sport (Bloom \& Stevens, 2002; Stevens \& Bloom, 2003) environments and have led to some positive results. For example, Stevens and Bloom investigated the effectiveness of a team-building intervention program with an elite softball team and found that the intervention group reported significantly higher perceptions of cohesiveness after the intervention than the control group. In another study, Bloom and Stevens used a direct team-building intervention approach with a university equestrian team. The intervention focused on leadership, team norms, communication, and competition issues. Results of the qualitative portion of their study revealed improved team harmony and closeness and improved coach-athlete and athlete-athlete relationships.

Although the benefits of team building have been established in exercise, sport, and physical education settings, nearly all the research has been conducted from an athlete's perspective. This is unfortunate in that it would be equally important to examine coaches' perceptions of intervention programs because it is often these individuals who administer the team-building programs. In fact, research on coaches has shown that they influence the degree of enjoyment experienced by youth and their desire to continue participating in sport (Scanlan \& Lewthwaite, 1986; Smith \& Smoll, 1990) through their goals, values, attitudes, and behaviors (Smith \& Smoll, 1990, 2002; Weiss \& Gould, 1986). Thus, it might be concluded that coaches impact whether youth-sport participants have a positive sporting experience, and acquiring their perceptions might be important for understanding youth-sport physical activity patterns.

\section{Methods}

\section{Participants}

Eight Peewee-level ice hockey coaches from a large metropolitan Canadian city participated in this study. The Peewee level was chosen because the players are age 11-13 years, an age when there is a decline in youth-sport involvement (Hedstrom \& Gould, 2004; Lindner \& Johns, 1991). Coaches represented all levels of competition 
in the Peewee division, including one AA coach (the highest level), two BB coaches, three A coaches, and two B coaches (the lowest level). All coaches were certified through the Coaching Association of Canada (CAC). Table 1 provides a summary of the 8 participants' hockey backgrounds and coaching accomplishments before the start of the study.

\section{Procedures}

Initially, the president of the hockey association was contacted by phone, informed of the nature of the investigation, and asked permission for the coaches to participate in the study. Once consent was obtained from the association, contact was made with the nine Peewee-hockey coaches who were each invited to take part in this study. The 8 who agreed to participate each completed a consent form and demographic questionnaire. Consent forms were signed by the players and their parents before the first team-building activity. These activities took place before or after games and practices, in the dressing rooms, or in larger rooms of the arena.

\section{Team-Building Program}

The conceptual framework of team building developed by Carron and Spink (1993) served as the theoretical base from which this examination embarked. The teambuilding program used a four-phase approach consisting of an introductory phase, conceptual phase, practical stage, and intervention phase (Carron \& Spink). The first three phases occurred in a 2-hr introductory workshop before the start of the season. The fourth phase consisted of the delivery of the team-building activities that occurred throughout the regular season.

\section{Table 1 Background and Accomplishments of Each Coach}

\begin{tabular}{lrrrrrrrr}
\hline & C1 & C2 & C3 & C4 & C5 & C6 & C7 & C8 \\
\hline Current coaching level & PW & PW & PW & PW & PW & PW & PW & PW \\
$\begin{array}{l}\text { Highest level of } \\
\text { organized hockey played }\end{array}$ & J & M & AR & M & M & None & J & M \\
$\begin{array}{l}\text { Coaching-certification } \\
\text { level (from 1 to 5) }\end{array}$ & 2 & 2 & 2 & 2 & 1 & 2 & 1 & 1 \\
$\begin{array}{l}\text { Number of seasons as } \\
\text { head coach }\end{array}$ & 10 & 10 & 8 & 14 & 7 & 5 & 8 & 2 \\
$\begin{array}{l}\text { Highest level coached } \\
\text { M AA }\end{array}$ & M CC & PW & PW & PW & PW & B A & PW \\
$\begin{array}{l}\text { Number of playoff } \\
\text { championships }\end{array}$ & 7 & 2 & 4 & 7 & 1 & 0 & 0 & 0 \\
$\begin{array}{l}\text { Number of tournament } \\
\text { championships }\end{array}$ & 2 & 3 & 1 & 0 & 2 & 3 & 0 & 0 \\
\hline
\end{tabular}

Note. $\mathrm{PW}=$ Peewee; $\mathrm{J}=$ Junior; $\mathrm{M}=$ Midget $\mathrm{AR}=$ adult recreational league $\mathrm{B}=$ Bantam; none = no playing experience. Levels 1 through 3 of the coach education program in Canada are designed for coaches of community, school, and club-sport programs. Levels 4 and 5 represent the top levels of coaching and are designed for coaches of elite national- and international-caliber athletes. 
The introductory phase involved the researcher explaining the rationale for the team-building program. As Carron and Spink (1993) noted, coaches exhibit greater motivation and adherence to the team-building program if they understand the rationale behind the intervention. As a result, the construct of team building was introduced and explained to coaches. In addition, results from previous studies describing the general benefits of team building were discussed, including enhanced group stability and willingness to share responsibilities for group outcomes.

A Web site created specifically for this study was explained to coaches at the team-building introductory workshop. The site was designed to give coaches and members of the research team access to the descriptions of the team-building activities and the dates and locations of the team-building sessions. The site also provided coaches with pre- and postintervention forms they were required to complete.

Second, the conceptual stage required the researcher to present coaches with Carron and Spink's (1993) conceptual framework of team building. The benefit of presenting the team-building model was threefold (Carron \& Spink). First, complex constructs were communicated and simplified. Second, it was easier to demonstrate how the individual components of the model were related to each other. Third, the focus of the five factors (i.e., distinctiveness, team norms, individual positions, interaction and communication, and individual sacrifices) that were targeted for intervention were identified.

In the practical stage, the researcher provided coaches with an outline and general description of the team-building activities they were required to implement with their teams. All the activities were designed to be fun and to include a range of intellectual, physical, and emotional problem-solving tasks for youth focused on teamwork, organization, communication, and cooperation (cf. Glover \& Midura, 1992; Midura \& Glover, 2005). These activities were structured based on the five factors of Carron and Spink's (1993) conceptual framework for team building. Conceptualization of the team-building program and activities can be found in Table 2.

Finally, the intervention phase was explained to the coaches at the workshop, and then they were expected to carry out the activities throughout the season. During the season, each coach was required to (a) lead five team-building activities lasting approximately $30 \mathrm{~min}$ each, (b) complete a preintervention form within $48 \mathrm{hr}$ of

\section{Table 2 Conceptualization of the Team-Building Program}

\begin{tabular}{lll}
\hline $\begin{array}{l}\text { Conceptual link to } \\
\text { Carron and Spink's } \\
\text { (1993) model }\end{array}$ & $\begin{array}{l}\text { Factors from Carron } \\
\text { and Spink's (1993) } \\
\text { model }\end{array}$ & $\begin{array}{l}\text { Team-building activity-from Glover } \\
\text { and Midura (1992) and Midura and } \\
\text { Glover (2005) }\end{array}$ \\
\hline Group processes & $\begin{array}{l}\text { Interaction and } \\
\text { communication }\end{array}$ & $\begin{array}{l}\text { Alphabet balance beam } \\
\text { The Web }\end{array}$ \\
& $\begin{array}{l}\text { Individual sacrifices } \\
\text { Distinctiveness } \\
\text { Troup environment }\end{array}$ & $\begin{array}{l}\text { Caution: construction zone } \\
\text { Troup structure }\end{array}$ \\
& $\begin{array}{l}\text { The maze } \\
\text { Individual positions }\end{array}$ & The rope challenge \\
\hline
\end{tabular}


each team-building activity, and (c) complete a postintervention form within 24 $\mathrm{hr}$ after each team-building activity. One team-building activity was implemented approximately every 3 weeks. Coaches were encouraged to use Smith and colleagues' (Smith, Smoll, \& Curtis, 1978, 1979; Smith \& Smoll, 1997, 2002) positive principles of coaching while their players were engaged in the team-building activities. In addition, the coaches were expected to hold a 5-15 min debriefing with their athletes after each team-building activity (cf. Socha, Potter, \& Downey, 2003). Verbal guidelines were given to direct these debriefings.

\section{Instruments}

Three qualitative data-gathering techniques were used to obtain data for the current study: pre- and postintervention forms, observational evaluations, and interviews. Patton (1990) has written extensively about the usefulness of employing various qualitative research techniques for program evaluation.

Pre- and Postintervention Forms. These forms allowed coaches to communicate their feelings and reflect on the research process by writing their thoughts and perceptions. Pre- and postintervention information was acquired via the Web site in two ways. First, coaches completed a preintervention form within $48 \mathrm{hr}$ before each team-building intervention by answering questions related to team record, team environment, relationships among athletes, and coach-athlete relationships. Second, coaches answered questions related to their thoughts and feelings about the quality of the intervention and their perceptions of athlete receptiveness and attentiveness to each team-building activity by completing a postintervention form within $24 \mathrm{hr}$ of each team-building session.

Observational Evaluations. This data-collection technique was used to provide a better understanding of the context in which the team-building activities occurred. In particular, 10 trained research assistants observed, identified, and described contextual (e.g., who was present) and behavioral (e.g., coaches' use of positive reinforcement) information to the research investigators. Each coach was observed a minimum of four times during the season by a different research assistant.

In this study, the research assistants were eight undergraduate students in the department of kinesiology and physical education and two undergraduate students in the department of psychology. All 10 students had taken an undergraduate sport psychology course and were required to (a) attend the introductory workshop given by the principal investigator, (b) attend biweekly research meetings led by the principal investigator, (c) attend team-building sessions over the course of the season, (d) record field notes on behavioral and contextual information during team-building sessions, and (e) elaborate on field notes and forward them to the principal investigator within $24 \mathrm{hr}$ postintervention. Because there were 8 coaches, five different team-building activities, and 10 research assistants, each assistant observed a minimum of four team-building sessions. A rotating schedule was in effect to ensure that observers did not become immune to the social and leadership dynamics of a particular team setting; in addition, it allowed a variety of information from different perspectives to emerge (Patton, 1990). 
Interviews. All the coaches participated in individual exit interviews lasting between 40 and $90 \mathrm{~min}$. These semistructured interviews took place during the last month of the regular season. A four-part interview guide with a series of openended questions was created specifically for this study. First, introductory questions were designed to initiate the discussion (e.g., "Describe your evolution into coaching") and to preface the main topic of this study. The second part consisted of seven key questions focused primarily on coaches' roles, opinions, and feelings about the outcomes of the team-building intervention program (e.g., "What did you feel your athletes gained from this team-building program?" "Did you, as a coach, gain something from the team building program?"), as well as the different circumstances or factors that influenced the dynamics of the team (e.g., "Were there any unique circumstances that occurred with your team this year?" "Were there any other team functions or activities that you did with your team that can be classified as team building?"). The third part included a summary question to tie together the most salient outcomes of the program (i.e., "In your opinion, what are the three most important qualities that you felt emerged from this program?"). Finally, the fourth part included questions intended to give participants the opportunity to provide any additional information or share any concerns. Key questions, interview probes, and follow-up questions were used to direct the discussion to principal topics of the study, and add detail, depth, or clarity in order to pursue central themes discovered and explore implications of what had been said (Rubin \& Rubin, 1995). The participants' anonymity was protected through the use of a coding system that replaced each name with a number $(\mathrm{C} 1-\mathrm{C} 8)$; in addition, any identifying information (e.g., name of team) was also changed.

\section{Data Analysis}

Analysis of the pre- and postintervention forms and observational evaluations was ongoing throughout the study and was continually reflected on as the study progressed. These two data sets complemented the primary source of data, which were the interviews. Analysis of the interview data was inductive and followed the guidelines outlined by Côté, Salmela, and Russell (1995), which consisted of three main steps: creating tags, creating properties, and creating and conceptualizing categories.

The interview transcripts were divided into 425 quotes called meaning units (MU) that were separate pieces of text expressing a single idea, concept, or piece of information (Tesch, 1990). Next, each MU was given a tag based on its content. Similar MU received the same tag. A total of 53 tags emerged from the data. After this, similar tags were divided into larger groupings called properties. Each newly formed property was also named or tagged according to the common features of their shared MU (Côté et al., 1995). This process produced nine properties. Finally, the last level of classification consisted of grouping similar properties into higher level divisions called categories. Four categories emerged from this process. The data were examined until saturation was reached and no new level of information emerged at any level of classification.

\section{Trustworthiness}

The trustworthiness of the data was improved by following the suggestions of Lincoln and Guba (1985). First, member checks were used to allow participants 
to verify researchers' understanding of the information they provided (Lincoln \& Guba). Of the eight transcripts that were sent back to participants, six changed nothing and two did not reply.

Second, peer review was used to improve the credibility of this study (Lincoln $\&$ Guba, 1985). The peer-review process took place independent of the research team. A peer assistant (who was not a member of our research team) examined $25 \%$ of the MU created by the research team from the data and matched each MU with a tag previously labeled by the research team. A reliability rate of $92 \%$ was reached for analysis of the MUs. After some discussion between the research team and the peer assistant, it was agreed that four of the tags would be recoded because the original tags did not adequately reflect the meaning in the passages. A second step consisted of classifying the 53 tags into nine properties. A $98 \%$ rate of reliability was achieved. At the next stage, the nine properties were grouped in four categories by the peer reviewer with a reliability rate of $100 \%$.

Third, prolonged engagement was used by the principal investigator to learn the culture and build the trust of participants (Lincoln \& Guba, 1985). In this study, prolonged engagement was achieved by having the principal investigator meet with coaches at the onset of the season and by attending all of the team-building sessions. In addition, the principal investigator maintained a relationship with coaches by contacting them over the telephone and through e-mail and by attending some games.

Finally, triangulation, or cross-checking, was also used to ensure credible findings. In this study, three qualitative data-gathering techniques were used to obtain information on the perceptions of the youth ice hockey coaches. First, observations of coaches' behaviors were noted by the research team. Second, information was acquired by having coaches fill out a pre- and postintervention form on the Web site for each team-building activity. Finally, a semistructured interview was conducted with each coach after the completion of the regular season.

\section{Results}

The eight interviews resulted in a total of 425 MUs. From this, four higher order categories emerged from the analysis and were labeled coach outcomes, team outcomes, athlete outcomes, and program involvement and assessment. Quotes from the interviews will be provided, as well as excerpts from both the observational evaluations of the research assistants and the pre- and postintervention responses from the coaches. Each quote is followed by a label $(\mathrm{C} 1-\mathrm{C} 8)$ to credit the participant who provided the quotation.

\section{Coach Outcomes}

Coach outcomes included the skills coaches gained (e.g., communication) as a result of their participation in the team-building program. Six out of eight coaches stated that they were better able to communicate with their athletes as a result of their involvement in the team-building program. Specifically, coaches noted they were better able to break down complex tasks and explain instructions more succinctly: 
Having directly participated in the team-building sessions made it more of a teaching and learning experience for me. I communicate better with my players now and I communicate with them on their level. I'm not always the most articulate person, but I became a better coach by learning how to explain things to the players at their level of understanding. (C2)

In fact, observations of coaches' communication skills were also described by the research assistants. These observations appear to confirm what the coaches were articulating as viewed by one research assistant:

Having seen this coach during his or her first intervention, I can report improvements in [his or her] communication skills. During the first intervention, [he or she] continuously looked at [the principal investigator] to make sure [he or she] was explaining the instructions correctly. The players asked a lot of questions to make sure they understood the activity. However, during today's session, [he or she] explained the instructions very clearly and no athlete needed to clarify directions because they seemed to understand right away. The coach seemed more comfortable and joked around with the players during the explanations. The athletes responded to the perceived confidence of the coach and got right into the activity.

Five coaches also reported improving the quality of feedback given to their players. Coaches found they reflected more on the appropriateness of their feedback and highlighted the importance of articulating positive, rather than negative, comments to their athletes:

So many times it's easier for the negative [comments] to come out. Because I had to explain and participate in the activities, I learned to not use negative comments and say, "Okay, it's not working well but still, let's keep going, let's do it, let's be positive." I'm positive almost all the time, but I learned even more to be positive and patient with the group that I have. Sometimes I just wanted to say, "You aren't doing it right" but then I asked myself, "Why aren't they doing it right?" The activities permitted me to calm down, cool down, and take my time to analyze the situation before coming up with my feedback, which is something I didn't always do on the bench. The team-building program permitted me to come up with a positive way of saying something and to get the negative out of my head. I've really learned to deliver the same message but in a positive way. (C5)

Some of the observations by the research assistants also noted the quality of the feedback the coaches gave their players, as noted in the following comment:

[Coach] gave large amounts of positive feedback and encouragement to his/her players during today's session. He or she was very enthusiastic and very positive. After giving instructions [he or she] circulated around the room, highlighting what the players were doing well and giving small tips for improvement. Some of the frequent comments included, "You're doing great buddy! Good 
job! Keep up the great work! Wow, I'm so impressed with what I'm seeing from you all!" While [he or she] gave his or her players a lot of support, [he or she] tended to increase feedback when players' attentions waned, for example, when they would begin looking onto the ice through the window.

\section{Team Outcomes}

Team outcomes included the benefits of participating in the team-building program. It included aspects such as team bonding and the team's ability to work together.

All coaches elaborated on team outcomes related to their involvement in the team-building program. One commonly discussed outcome affecting the entire group was the degree of bonding that took place between players:

All activities involving situations where the kids work together and do things together to achieve a common goal help the team environment. The teambuilding exercises that we went through were all team oriented and emphasized working together for success. These are good qualities to have when you are trying to build a hockey team. (C5)

The players really enjoyed the team-building activities. They were bonding while participating in the activities even though they didn't know they were doing it. They were forming teams, forming friendships, working together, and hopefully learning at the same time that they have to work together whether it's on the ice or off the ice and in anything they do in life. The kids definitely bonded and got closer together as a group. (C8)

On the postintervention forms, 6 coaches also referred to athletes' increased abilities to work together. Participants noted most activities required athletes to work as a unit to accomplish tasks:

This team-building activity was most definitely beneficial. The players realized they had to work as one unit in order to attain their goal. They were forced into a situation [in which] they had to use skill sets that were often stressed by the coaches, but not always used, like working as a group. As coaches we preach this, but too often players fail to use this on the ice or on the bench. In these activities though, each player had to inform the other players around him of his intentions. Working together they became more successful and began applying their new knowledge and newfound experiences to help the next player who had to attempt the same move. . . . We talk about it, but these activities really bring the "work together" aspect out. (C1)

\section{Athlete Outcomes}

Athlete outcomes referred to what the coaches believed the athletes gained from participating in the team-building program. More specifically, this category included affective (e.g., feelings, attitudes, and values), and cognitive (e.g., intellectual 
and thinking-related skills) outcomes that athletes experienced as a result of their involvement in the intervention program.

All coaches identified athlete enjoyment as the most popular athlete affective outcome of the team-building program. Coaches stated athletes looked forward to the team-building activities and derived pleasure from their involvement in the program:

The kids had a great time; they had fun doing the activities. They weren't something that was forced on them, where they had to sit there and go "Oh, we've got to go and do that psychology thing again?" No, it was like, "Okay coach, when's the next one?" They were very excited about it and I think that's something that a lot of [adults] forget. They are kids and that they want to have fun. I think the athletes had a blast doing the team building activities. (C1)

I don't think the kids enjoyed [the program], I know they did. I know how much fun they had. As I've said a couple of times already, the kids were really excited after each and every session. They came into the dressing room and said "Oh, did you see what he did, and he fell," and so on, so they really enjoyed the activities. It was good for them and they really enjoyed everything they did. (C7)

Another athlete affective outcome discussed by coaches was perseverance. Coaches felt players persisted in the challenges until they had succeeded, regardless of how difficult tasks were at times:

The players definitely learned about persistence and perseverance from taking part in these team-building activities. Not only did they learn to help each other out, they learned how much fun it was to succeed at something difficult together. This is the most important thing they can learn: that no matter how hard something is, never quit. They know it's very easy to quit when they have a problem, but these kids here didn't quit because they had somebody else helping them do something difficult. (C5)

Athlete cognitive outcomes involved the intellectual or thinking-related skills and outcomes coaches felt athletes experienced because of their involvement in the team-building program. For instance, 5 coaches articulated that athletes' abilities to reflect on potential solutions and solve problems improved because of their participation in the activities:

I was really impressed with how some of the activities were made. They forced the kids to think about what they were going to do before doing it. I found they were really determined to figure it out together and make it right to the end. They all gave $100 \%$ and it went well. They really got better at figuring things out and persisting as the activities went on. (C8) 
Coaches also commented on their postintervention forms about some of the cognitive benefits of the team-building program. For instance, one coach noted,

I was really impressed with the way I saw the athletes problem-solving. They were decent in the first couple of activities but got a lot better at solving these puzzles as the activities went on. They were thinking better. (C1)

Three coaches also felt athletes' abilities to focus improved because of their participation in the intervention program. Likewise, improvements in focus were noted not only during the activities but, in some cases, also on the ice:

In a lot of the team-building activities, the players really had to focus and mentally concentrate. This is one of the reasons why I really enjoyed the activities. The importance of focus is something that a lot of players don't realize; there's a lot of mental activity that takes place when you're a hockey player at this level and some just aren't ready for that. Some of them just say, "Okay, let's go," and off they go. These guys really had to focus during the sessions and I found the team-building activities really did improve their focus and made them realize its importance. I definitely saw this improvement on the ice when we'd be explaining something or talking to them. (C1)

Coaches spoke extensively about athlete retention of team-building concepts referred to during activities and team debriefings. More specifically, coaches conversed with athletes about the need for communication, trust, listening, and teamwork to accomplish the team-building challenges. For example, "The players were listening to what the coaches and their teammates said" (C1). Coaches also referred to athlete retention on their pre- and postintervention forms. For instance, "The program is great, but the children do not realize it yet. It will take much more time, more patience, and more repetition to do the job!" (C4).

Coaches had mixed opinions about the transfer of concepts between teambuilding activities and on-ice and off-ice events. Three coaches believed that team-building concepts did not transfer or did so only temporarily. For example, "I think that the positive messages that came out of the program transferred to the dressing room but only in the short term" (C6).

In contrast, 5 coaches were adamant that transfer occurred. They discussed how athletes took concepts learned and applied them outside team-building contexts. The following quotation summarizes the opinions of these coaches:

In the blindfolded team-building activity, the players had to communicate between each other, and you could tell that some kids did not have the same communication skills as others because they were going "left, right, no forward," and the poor kid that was blindfolded didn't know where to go. They didn't use names and they didn't communicate the instructions as well as they should have. [Now, however,] they are communicating on the ice better 
because they are calling each other's names, so we took that and we flipped it over. I said, "Guys, if you understand this message about how important communication is, we'll have a better season." They picked the concept up nicely in the activity and we carried it to the ice. (C2)

\section{Program Involvement and Assessment}

Program involvement and assessment were the essence of the team-building program. More precisely, it involved the coaches' roles delivering the team-building activities and their evaluation of the intervention program.

All coaches reported they prepared for team-building activities the same way they would for a practice or a game. Likewise, 3 coaches mentioned they were nervous before the first activity but relaxed and began to enjoy explaining challenges to their athletes as the season progressed. For example, one coach noted,

I didn't feel confident delivering the first one or two team-building activities. Even with board games, I needed people to show me. I needed to see or do to learn, that's why the researcher had to help me a lot before the activities. It did get a little easier and maybe I paid a little more attention, too, as we went through them. (C3)

Coaches discussed the debriefings they were asked to do with their athletes after team-building activities. Six coaches reported they conversed with their team immediately after sessions regarding outcomes and lessons learned as a result of their involvement. These coaches felt the debriefing sessions were crucial, as evidenced by the following quotation:

I thought the debriefing sessions were very beneficial; in fact they were probably the most important part of the whole exercise. Players can do the activities, and they have some benefits, but do the athletes realize what the benefits are? Does the coach realize what the benefits are? And sometimes they would just discuss it, and you'd sit there and go "Hey, yeah! Remember when I said that last game? You were listening!" So those were very very important to us. (C1)

A research assistant also noted the techniques used by coaches to debrief athletes after sessions. For instance:

After the activity, the coach sat the players down outside the room and talked about the intervention. He or she pointed out the most important aspects of the activity and how they applied to hockey. [He or she] asked what the kids learned, why and what they thought was important, and he or she gave a lot of space for them to share their views about the intervention. [He or she] talked for 10 minutes about the importance of communication, listening, team building, trust, and encouraging your teammates, and then gave examples on how to use these skills on the ice. The debriefing the coach had with his or her players seemed really productive as the players continuously gave on-ice examples, pointed out elements of the intervention that could help build team spirit, and illustrated how they could apply them to hockey. 
Evaluation of the team-building program encompassed coaches' initial impressions of the team-building program. Five coaches were enthusiastic about their involvement directly from the introductory workshop and predicted the potential benefits it would have for their teams. For example, "I knew this team building was going to be good for our team right from the start. I was excited to begin and see what kinds of things we'd get out of it" (C1).

In contrast, 3 coaches wondered what their athletes' reactions would be. These coaches were skeptical about the program because they did not know what to expect, as illustrated by the following quotations:

At the beginning I was anxious. I wasn't sure where [the program] was going to lead, and that made me a little nervous. I wondered, "How's my team going to react to this? How am I going to be ready for this? Do I really feel like doing this?" Honestly, I didn't know myself what to expect. (C5)

I was very skeptical about the program, especially after the first activity. I'm not sure that I understood the intent behind it all. Certainly for the first activity, I didn't understand my role. I didn't know how far I could go leading the group. "Should I say this?" "Should I do that?" I became more comfortable with what my role was as a facilitator, as a leader, as we went along. That's something that I should have clarified that at the beginning, but that's me too. I'll go headfirst into something without looking at it. (C2)

Although some of the coaches were initially a little anxious about being involved in the team-building program, all the coaches expressed that they were glad to have participated and said they would get involved if it was offered again. In addition, although coaches revealed that athlete participation in the team-building activities was not mandatory, they reported that all players attended activities unless they were not present for the scheduled practice or game. Coaches said the program could be effective across all age groups, and they recommended the team-building program to anyone involved in youth hockey, as evidenced in the following three quotes: "This program should never be abolished! In fact it should be mandatory for every team" (C5). "This program is definitely something I would recommend to other teams and coaches. I would do the team-building program again in a heartbeat-no questions asked" (C3).

I would say that I did gain something from this experience. I learned that I should give any new idea a chance before I shut it out. Something which does not look worthwhile on the surface may eventually lead to good things if you try them out. (C8)

Coaches also repeatedly endorsed the team-building program on their postintervention forms. To be specific, all participants highlighted the value of each teambuilding session and explained how individual activities assisted their teams:

Anything we do together is positive; these team-building activities prove this. What was interesting was that everyone listened to one another. It's really interesting to see. One player seemed to dominate the exercise and that player is not normally a leader. [He or she] clearly he had a knack for the memory 
part of this game, and others followed suit and participated. Another player knew memory games were not [his or her] forté but had no problem following directions from others. These activities really bring out all the different sides of kids. We, as coaches, enjoy them for that. We'd do them anytime. (C2)

They have started to use the same words that I used to coach them through the process. "Support" has become the new buzzword around the team. Our team-building exercises have a lot to do with our on-ice successes. (C7)

\section{Discussion}

The results of the current study provide preliminary support for the benefits of a season-long team-building intervention program as perceived by youth-sport coaches. In particular, coaches believed that athletes enjoyed the team-building experience and improved and acquired a variety of important life skills and abilities (e.g., listening, teamwork) because of their participation. Likewise, coaches felt that their own communication skills improved as a result of their involvement in the team-building program. Finally, the coaches noted that athletes bonded during activities and improved their abilities to work together as a group.

Coaches felt they were better able to communicate with their players as they went through this program, including breaking down complex tasks and explaining instructions more succinctly. Past research has supported the importance of effective coach-athlete communication (e.g., Smith et al., 1978, 1979) and has identified successful communication as a key element in the effectiveness of leaders (Carron, 1982). In addition, the production of coherent and acceptable leadership and the organization of efficient group meetings have been identified as two of the six benefits of team-building interventions (Woodcock \& Francis, 1994). Thus, it was not surprising that coaches reported they were better able to explain complex tasks and activities to their athletes as the sessions progressed.

These results contribute to previous research identifying youth-sport coaches as playing a critical role in the creation of a positive sporting environment (e.g., Bloom, 2007; Smith et al., 1979; Smith \& Smoll, 1997, 2002). For instance, Smith and colleagues found that youths enjoyed their sporting experience to a greater extent when there were high levels of coach supportive behaviors. Furthermore, Smith et al. identified the use of positive reinforcement and encouragement as ideal behaviors of youth coaches. Thus, as in previous research involving structured coach training and intervention programs (e.g., Smith et al., 1978, 1979; Smith \& Smoll, 1997, 2002; Smith, Smoll, \& Barnett, 1995), the team-building program in this study appeared to be successful in promoting desirable coaching behaviors.

All coaches in the current study emphasized several team-related outcomes that resulted from their involvement in the intervention program. Specifically, coaches discussed how activities strengthened the bond between players and improved athletes' abilities to work together as a unit. In fact, all coaches reported the development of team unity as the primary team outcome of the intervention program. This finding is similar to past research examining the beneficial effects of team building (e.g., Bloom \& Stevens, 2002; Bloom, Stevens, \& Wickwire, 2003; Gould, Guinan, Greenleaf, Medbery, \& Peterson, 1999; Stevens \& Bloom, 2003; 
Voight \& Callaghan, 2001). For instance, Gould and colleagues used a focus-group methodology and found that team-building exercises in training programs increased the development of team cohesion.

All coaches in the current study emphasized the enjoyment they believed athletes experienced during the team-building activities. In fact, coaches identified athlete enjoyment as the most popular outcome of the team-building program. This finding contributed to previous research recognizing player enjoyment as a benefit of team-building interventions (Woodcock \& Francis, 1994). Perhaps this finding is not surprising given that all the activities were purposely chosen to accentuate elements of teamwork and fun for youth (cf. Glover \& Midura, 1992; Midura \& Glover, 2005). Moreover, these activities involved intellectual, physical, and emotional problem-solving tasks and challenges that were novel experiences, which athletes had never experienced with their coaches or teammates. In fact, members of the research team reported that athletes expressed amusement and displayed energy and interest during nearly all the team-building sessions. Although not directly related to athlete enjoyment, the chosen activities were also conceptually linked to all elements of Carron and Spink's (1993) team-building model. More specifically, the activities focused on the group-process (i.e., interaction and communication, individual sacrifices), the group environment (i.e., team distinctiveness and group structure), and the group-structure (i.e., team norms, individual positions) components of the team-building model.

The higher order category-program involvement and assessmentencompassed the essence of the team-building program. Hence, it included coaches' roles in the delivery of the team-building activities, as well as their analysis of the intervention program. All coaches in the current study confirmed they enjoyed their roles and appreciated their involvement in the program. These findings support the use of the indirect approach to team building at the youth-sport level, whereby the sport psychologist works directly with the coach, who is then responsible for the delivery of the team-building activities and techniques (cf. Carron \& Spink, 1993; Voight \& Callaghan, 2001). Moreover, all coaches endorsed the team-building program and reported that it would be effective with athletes of all age and ability levels. Furthermore, because of the numerous positive outcomes participants felt emerged from the team-building activities, all coaches expressed interest in taking part in the program in future seasons and reported they would administer their own off-ice team-building activities if the program was no longer available. Overall, these findings contribute to previous research identifying team building as a crucial and effective process in a team's development (e.g., Bloom et al., 2003; Stevens \& Bloom, 2003; Voight \& Callaghan). More specifically, the results of the current study support Bloom and colleagues' suggestion that team-building programs need to be properly planned, organized, and implemented to foster a positive sporting environment.

Despite the many benefits that emerged from this study, there are a number of future directions research could take. The current study could be replicated with other team sports such as basketball or football, as well as with dyadic sports such as rowing or tennis, to explore possible sport differences. Gender differences between female teams, male teams, and mixed-sex teams could also be investigated, ideally with larger sample sizes. In addition, the study could be replicated examining only female coaches' perceptions. 
To summarize, the current exploratory study is of interest to the youth-sport community because it explains coaches' thoughts and feelings of the benefits and impact of a team-building intervention program for young athletes. In particular, the current study can help coaches improve their coaching skills and abilities by learning about the preparation, implementation, and commitment required for the execution of an effective team-building program. In addition, coaches might gain knowledge of the advantages of a season-long team-building intervention for themselves, their athletes, and their teams. With these results, coaches might become more effective youth leaders and, consequently, might enhance personal and team satisfaction and performance. Furthermore, in a more enjoyable and satisfying environment, youth-sport athletes might be more likely to continue to participate in regular physical activity as they progress toward adulthood.

\section{Acknowledgments}

This research was supported from a grant received by the Social Sciences \& Humanities Research Council of Canada. The authors would like to thank Dr. Pierre Trudel for his insightful feedback on this project.

\section{References}

Beer, M. (1980). Organizational change and development: A systems review. Glenview, IL: Scott, Foresman.

Bloom, G.A. (2007). Coaching psychology. In P.R.E. Crocker (Ed.), Introduction to sport psychology: A Canadian perspective (pp. 239-265). Toronto, ON: Pearson.

Bloom, G.A., \& Stevens, D.E. (2002). A team-building mental skills training program with an intercollegiate equestrian team. Athletic Insight, 4. Retrieved from http://www. athleticinsight.com/Vol4Iss1/EquestrianTeamBuilding.htm

Bloom, G.A., Stevens, D.E., \& Wickwire, T.L. (2003). Expert coaches' perceptions of team building. Journal of Applied Sport Psychology, 15, 129-143.

Brawley, L.R., \& Paskevich, D.M. (1997). Conducting team building research in the context of sport and exercise. Journal of Applied Sport Psychology, 9, 11-40.

Carron, A.V. (1982). Cohesiveness in sport groups: Interpretations and considerations. Journal of Sport Psychology, 4, 123-138.

Carron, A.V., Hausenblas, H.A., \& Estabrooks, P.A. (2003). The psychology of physical activity. New York: McGraw-Hill.

Carron, A.V., \& Spink, K.S. (1993). Team building in the exercise setting. The Sport Psychologist, 7, 8-18.

Coaching Association of Canada. (2007). Overview of the Coaching Association of Canada. Retrieved from http://www.coach.ca/eng/about_cac/overview.cfm

Côté, J., Salmela, J.H., \& Russell, S. (1995). The knowledge of high-performance gymnastic coaches: Methodological framework. The Sport Psychologist, 9, 65-75.

Ebbeck, V., \& Gibbons, S.L. (1998). The effect of a team building program on the selfconceptions of Grade 6 and 7 physical education students. Journal of Sport \& Exercise Psychology, 20, 300-310.

Estabrooks, P.A., \& Carron, A.C. (1999). Group cohesion in older adult exercisers: Prediction and intervention effects. Journal of Behavioral Medicine, 22, 575-588.

Etnier, J.L., Salazar, W., Landers, D.M., Petruzzello, S.J., Han, M., \& Nowell, P. (1997). The influence of physical fitness and exercise upon cognitive functioning: A meta-analysis. Journal of Sport \& Exercise Psychology, 19, 249-277. 
Gibbons, S.L., \& Black, K.M. (1997). Effect of participation in team-building activities on the self-concepts of middle school physical education students. Avante, 3, 46-60.

Glover, D.R., \& Midura, D.W. (1992). Team building through physical challenges. Champaign, IL: Human Kinetics.

Gould, D., Guinan, D., Greenleaf, C., Medbery, R., \& Peterson, K. (1999). Factors affecting Olympic performance: Perceptions of athletes and coaches from more and less successful teams. The Sport Psychologist, 13, 371-394.

Haskell, W.L. (1994). Physical/physiological/biological outcomes of physical activity. In H.A. Quinney, L. Gauvin, \& A.E.T. Wall (Eds.), Toward active living (pp. 17-23). Champaign, IL: Human Kinetics.

Hedstrom, R., \& Gould, D. (2004). Research in youth sports: Critical issues status. Retrieved September 29, 2005, from Michigan State University Institute for the Study of Youth Sports Web page: http://ed-eb3.educ.msu.edu/ysi/project/CriticalIssuesYouthSports. pdf

Landers, D.M., \& Petruzzello, S.J. (1994). The effectiveness of exercise and physical activity in reducing anxiety and reactivity to psychosocial stressors. In H.A. Quinney, L. Gauvin, \& A.E.T. Wall (Eds.), Toward active living (pp. 77-82). Champaign, IL: Human Kinetics.

Lincoln, Y.S., \& Guba, E.G. (1985). Naturalistic inquiry. London: Sage.

Lindner, K.J., \& Johns, D.P. (1991). Factors in withdrawal from youth sport: A proposed model. Journal of Sport Behavior, 14, 3-18.

Midura, D.W., \& Glover, D.R. (2005). Essentials of team building: Principles and practices. Champaign, IL: Human Kinetics.

Newman, B. (1984). Expediency as benefactor: How team building saves time and gets the job done. Training and Development Journal, 38, 26-30.

Patton, M.Q. (1990). Qualitative evaluation and research methods (2nd ed.). Newbury Park, CA: Sage.

Prapavessis, H., \& Carron, A.V. (1997). Sacrifice, cohesion, and conformity to norms in sport teams. Group Dynamics. Theory, Research, and Practice, 1, 231-240.

Prapavessis, H., Carron, A.V., \& Spink, K.S. (1996). Team-building in sport. International Journal of Sport Psychology, 27, 269-285.

Riemer, H.A., \& Chelladurai, P. (1995). Leadership and satisfaction in athletics. Journal of Sport \& Exercise Psychology, 17, 276-293.

Riemer, H.A., \& Toon, K. (2001). Leadership and satisfaction in tennis: Examination of congruence, gender, and ability. Research Quarterly for Exercise and Sport, 72, $243-256$.

Rubin, H.J., \& Rubin, S.I. (1995). Qualitative interviewing: The art of hearing data. London: Sage.

Scanlan, T.K., \& Lewthwaite, R. (1986). Social psychological aspects of the competitive sport experience for male youth sport participants: IV. Predictors of enjoyment. Journal of Sport Psychology, 8, 25-35.

Smith, R.E., \& Smoll, F.L. (1990). Self-esteem and children's reactions to youth-sport coaching behaviors: A field study of self-enhancement processes. Developmental Psychology, 26, 987-993.

Smith, R.E., \& Smoll, F.L. (1997). Coach-mediated team building in youth sports. Journal of Applied Sport Psychology, 9, 114-132.

Smith, R.E., \& Smoll, F.L. (2002). Way to go coach! A scientifically proven approach to youth-sports coaching effectiveness (2nd ed.). Palo Alto, CAs: Warde.

Smith, R.E., Smoll, F.L., \& Barnett, N.P. (1995). Reduction of children's sport performance anxiety through social support and stress-reduction training for coaches. Journal of Applied Developmental Psychology, 16, 125-142. 
Smith, R.E., Smoll, F.L., \& Curtis, B. (1978). Coaching behaviors in Little League baseball. In F.L. Smoll \& R.E. Smith (Eds.), Psychological perspectives on youth sports (pp. 173-201). Washington, DC: Hemisphere.

Smith, R.E., Smoll, F.L., \& Curtis, B. (1979). Coach effectiveness training: A cognitive behavioral approach to enhance relationship skills in youth sport coaches. Journal of Sport Psychology, 1, 59-75.

Socha, T.L., Potter, T.G., \& Downey, P.J. (2003). The effect of team building on the physical self-concepts of grade 9 physical education students. Journal of Experiential Education, 25, 347.

Spink, K.S. (1995). Cohesion and intention to participate of female sport team athletes. Journal of Sport \& Exercise Psychology, 17, 416-427.

Spink, K.S., \& Carron, A.V. (1993). The effects of team building on the adherence patterns of female exercise participants. Journal of Sport \& Exercise Psychology, 15, 39-49.

Stevens, D.E., \& Bloom, G.A. (2003). The effect of a team-building program on cohesion. Avante, 9, 43-54.

Tesch, R. (1990). Qualitative research analysis types and software tools. New York: Falmer.

Voight, M., \& Callaghan, J. (2001). A team-building intervention program: Application and evaluation with two university soccer teams. Journal of Sport Behavior, 24, 420-431.

Wankel, L.M., \& Mummery, W.K. (1996). Canada. In P. De Knop, L. Engstrom, B. Skirstad, \& M.R. Weiss (Eds.), Worldwide trends in youth sport (pp. 27-42). Champaign, IL: Human Kinetics.

Weiss, M., \& Gould, D. (1986). Sport for children and youths. Champaign, IL: Human Kinetics.

Woodcock, M., \& Francis, D. (1994). Team building strategy. Hampshire, England: Aldershot.

Revision received: October 18, 2007 